\title{
A Systematic Review of Elastic Taping Effect of Patients with Stroke
}

\author{
Beom-Ryong Kim¹, Tae-Woo Kang ${ }^{2}$ \\ 'Department of Physical Therapy, Design Hospital, Jeonju; '2Department of Physical Therapy, Wonkwang University Hospital, Iksan, Korea
}

\begin{abstract}
This study was conducted to evaluate the effectiveness of taping intervention in patients with stroke through a review analysis of taping interventions used to enhance physical function and activity in patients with stroke. We searched randomized controlled trials using electronic databases. We also manually reviewed sources to identify additional relevant studies. Taping intervention is an approach to treat individuals with impaired physical function and activity. Taping interventions affect body functions by providing increased muscle strength, proprioceptive sensation, and range of motion, as well as decreased rigidity and pain. Taping interventions also improve walking, balance and arm functions, such as physical activity. Taping intervention for patients with stroke has been shown to be highly effective and is therefore strongly recommended; however, it is suggested that it be further developed to improve its efficacy as an intervention method and to create additional taping methods.
\end{abstract}

Keywords: Physical activity, Physical function, Stroke, Taping

서 론

뇌졸중은 뇌로 가는 혈관이 파열되거나 막혀 뇌의 기능장애를 일으 키는 질환으로, ${ }^{1}$ 이러한 뇌졸중 환자는 $80 \%$ 이상에서 편마비를 보인 다. ${ }^{2}$ 이러한 편마비 환자는 어깨와 몸통을 연결해주는 앞톱니근(serratus anterior)의 약화가 두드러지게 나타나고, ${ }^{3}$ 근 수축 패턴이 바뀌 게 되어 어깨뼈의 운동학적 변화를 보이며, ${ }^{4}$ 몸통근육의 약화와 몸 통의 비대칭적인 근 활성도로 인해 자세조절의 저하가 나타난다. ${ }^{5,6}$

테이핑은 비침습적, 비약물적인 방법으로 부작용이 적고 부착한 상태에서도 일상생활에 불편함이 없으며, ${ }^{7}$ 다른 중재방법과 병행하 여 적용이 가능하여 임상에서 근골격계 환자뿐만 아니라 뇌졸중과 같은 신경계 환자의 신체기능과 활동의 향상을 위해 적용되고 있다. ${ }^{8}$ 테이핑의 종류에는 관절을 고정하고 신체부위를 압박하여 가동범위 를 제한하여 불안정한 신체부위에 안정성을 증가시킬 수 있는 비탄 성 테이프와 탄력과 길이의 변화를 조절할 수 있는 테이프로 적용 부 위의 움직임에 따라 늘어나고 줄어드는 탄성 테이프가 있다. 탄성 테 이프는 모든 신체부위에 다양하게 적용할 수 있는 장점을 가지고 있 다. 특히 근육의 수축과 이완이 큰 부위에 비탄성테이프를 적용하면 혈관이나 신경을 압박하여 신경이나 혈관 장애를 일으킬 우려가 있 는 경우에 사용된다. 탄성 테이핑 부착 시 나타나는 일반적인 효과는
혈액과 림프순환 증진, 통증 감소, 신경학적 기능증진, 근육 불균형 감소, 고유수용감각 증진, 피부수용기 자극을 통한 근육 흥분성 증 진이 있고, ${ }^{9}$ 근 피로를 감소시키며, ${ }^{10}$ 뇌졸중 환자에게 적용할 경우 근 력과 기능적인 활동에 개선을 보인다. ${ }^{11,12}$

뇌졸중 환자에게 탄성 테이핑을 적용한 선행연구들을 살펴보면, $\operatorname{Kim}$ 등 $^{13}$ 팔 기능에 어려움이 있는 뇌졸중 환자의 어깨와 몸통에 테 이핑을 적용하여 팔 기능에 유의한 향상을 보고하였고, 손상측 팔의 근육군에 적용한 연구에선 팔 기능 향상과 통증 및 우울의 감소를 보고하였다. ${ }^{14}$ 또한, Park과 $\mathrm{Cho}^{15}$ 는 비 손상측에 몸통 교정 테이핑과 어깨뼈 설정 운동을 실시한 결과 팔 기능의 향상을 보고하였고, $\mathrm{Oh}$ 등 16 은 뇌졸중 환자의 무릎에 나선형 관절 테이핑과 넙다리네갈래근 테이핑을 적용한 결과 균형능력에 증가를 보였다.

이와 같이 뇌졸중 환자의 신체기능과 활동의 향상을 위해 다양한 탄성 테이핑 방법이 사용됨에도 불구하고 뇌졸중 환자에 대한 명확 한 탄성 테이핑의 효과를 제시하지 못하였다. 따라서 본 연구에서는 뇌졸중 환자에게 적용된 탄성 테이핑에 대한 연구들의 분석을 통해 뇌졸중 환자에 대한 탄성 테이핑의 효과를 조사하는 데 목표를 두었 고, 탄성 테이핑의 효과를 고찰하여 뇌졸중 환자의 중재프로그램 마 련을 위한 기초자료를 제공하고자 본 연구를 시도하였다.

Copylight (C) 2018 The Korea Society of Physical Therapy

This is an Open Access article distribute under the terms of the Creative Commons Attribution Non-commercial License (Http:// creativecommons.org/license/by-nc/4.0.) which permits unrestricted non-commercial use, distribution, and reproduction in any medium, provided the original work is properly cited. 


\section{본 론}

\section{1. 자료수집 및 분석}

1) 연구문헌 선정 기준

임상적 및 방사선학적으로 뇌졸중을 진단받은 환자를 대상으로 탄 성 테이프를 적용하여 근력, 경직, 고유수용성감각, 통증, 관절가동범 위와 같은 신체기능과 균형, 보행, 팔 기능과 같은 신체활동의 결과 변 수를 측정하여 실험군과 대조군으로 무작위배정 비교임상시험연구 를 대상으로 하였다. 결과가 도출되지 않은 프로토콜 연구, 다른 대상 자가 포함된 연구는 선정 대상에서 제외하였다.

\section{2) 검색과 자료 선정}

뇌졸중 관련 탄성 테이핑 적용의 최근 연구를 정리하고자 2008년부 터 2018년까지의 논문을 데이터베이스 PubMed, 학술연구정보서비 스(RISS), Google과 Google scholar를 통해 ‘Taping', 'Tape', 'Stroke'로 검 색하였다. 2 명의 저자가 검색된 논문의 전문을 확인한 후 연구문헌 선정 기준에 근거하여 연구를 선정하였다.

\section{2. 탄성 테이핑과 신체기능의 효과}

\section{1) 근력 증가}

뇌졸중의 증상은 손상 원인, 부위, 정도에 따라 다양하게 나타나며, 편마비, 운동장애, 감각결손의 문제 등 신경학적 문제가 복합적으로 나타난다.17 이러한 문제점들로 인해 움직임 감소와 활동제한으로 관 절가동범위 감소, 강직, 구축, 정렬의 변화가 나타나며, 특히 근육부 피 감소, 근섬유 단축, 운동단위 수의 감소와 같은 문제로 근력 약화 를 발생시켜 운동조절 능력이 저하된다. ${ }^{18}$ 뇌졸중 환자에게 있어서 발 목의 근력약화는 균형유지와 보행능력에 문제 및 기능적 회복의 저 하를 가져와 활동에 독립성을 제한시키는 문제를 발생시킨다. ${ }^{19}$ 따라 서 뇌졸중 발생 후 활동에 독립성의 회복을 위해 발목관절의 근력을
증진시키기 위한 운동을 통하여 보행능력을 증진할 수 있으며, ${ }^{20}$ 운 동과 함께 테이핑을 통해서 근력에 증가를 보일 수 있다. ${ }^{21}$ 뇌졸중 환 자에게 테이핑을 적용하여 근력 증가를 보고한 선행연구들을 살펴 보면 다음과 같다. Ekiz 등른 안쪽넓은근(vastusmedialis muscle), 가 쪽넓은근(vastuslateralis muscle) 및 넙다리곧은근(rectus femoris muscles)에 테이핑과 함께 4주간 일반적 재활프로그램을 병행하여 손상 측 다리의 등속성근력(Isokinetic muscle strength)에 유의한 증가를 보 고하였다. Kang과 $\mathrm{Kim}^{14}$ 은 손상측 팔의 벌림근(abductor)과 굽힘근 (flexor)에 테이핑을 적용하여 악력에 유의한 증가를 보였다. Lee와 $\mathrm{Lim}^{22}$ 은 어깨뼈 테이핑을 통해서 아래등세모근(lower trapezius)과 앞 톱니근의 근육 활동(muscle activity)에 향상을 보고하였다. 이러한 근 력의 증가는 뇌졸중 환자에게 테이핑을 적용함으로써 피부와 근육 의 근 긴장도가 감소되어 관절의 빼가 어긋나는 일이 감소되어 근력 이 증가된 것으로 사료되며, ${ }^{23}$ 뇌졸중 환자의 중재과정에서 근력의 증 가를 이끌어 내기 위해 테이핑을 적절하게 적용할 수 있다(Table 1).

\section{2) 경직 감소}

뇌졸중 환자의 경직은 비정상적 신체기능으로 속도에 의존하는 반사 에 영향을 주어 빠른 움직임에 반응하게 되는데 이렇게 만들어진 비 정상적 반사는 신체 일부를 뺏뺏하게 만든다. ${ }^{24}$ 경직이 심해질수록 하 지에서는 발목의 처짐과 뒤침 변형을 나타내게 된다. ${ }^{25}$ 뇌졸중 환자 는 발목관절의 발바닥쪽굽힘근(plantarflexor)의 경직이 심할 경우 보 행 시 하지가 앞으로 나가는 것에 장애를 주어 섬세한 운동기능을수 행하는 운동조절 능력, 비대칭적 자세, 그리고 균형과 보행능력 저하 의 장애와 같은 문제점을 가지게 된다. 26.27 이러한 경직을 감소시키고 신체능력을 개선시킬 수 있는 중재방법이 필요할 것이다. 테이핑은 상위운동신경(upper motor neuron) 손상환자에게 간편하게 적용하 여 경직 감소를 보일 수 있으며, ${ }^{28}$ 뇌졸중 환자에게 경직 감소 목적으 로 적용된 선행연구들을 살펴보면 다음과 같다. Park 등 29 은 장딴지

Table 1. Characteristics of the treatments in the included trials

\begin{tabular}{|c|c|c|c|c|}
\hline Study & Group & Sample size & Outcomes & Category \\
\hline Ekiz et al. ${ }^{12}$ & Quadriceps taping (elastic) & $24(12 / 12)$ & Isokinetic Test & Muscle strength \\
\hline Kang and $\mathrm{Kim}^{14}$ & Shoulder taping (elastic) & $50(25 / 25)$ & Grip dynamometer & Muscle strength \\
\hline Park et al. ${ }^{29}$ & Gastrocnemius taping (elastic)+balance trainer & $25(14 / 11)$ & Modified ashworth scale & Spasticity \\
\hline Carda et al..$^{30}$ & Ankle and thigh taping (elastic)+botulinum toxin type A & $69(24 / 27 / 18)$ & Modified ashworth scale & Spasticity \\
\hline Choi et al. ${ }^{41}$ & $\begin{array}{l}\text { Patella and quadriceps femoris taping (elastic) } \\
\text { +proprioceptive neuromuscular facilitation }\end{array}$ & $30(15 / 15)$ & Berg balance scale & Proprioception \\
\hline Lee et al. ${ }^{48}$ & Scapular girdle taping (elastic) & $40(20 / 20)$ & Visual analog scale & Pain \\
\hline Huang et al. ${ }^{49}$ & Shoulder taping (elastic) & $21(11 / 10$ & 11-point numerical rating scale & Pain \\
\hline Lee and $\operatorname{Lim}^{22}$ & Scapular taping (elastic) & $28(14 / 14)$ & Goniometry & Range of motion \\
\hline Oh et al. ${ }^{16}$ & Knee taping (elastic) & $36(12 / 12 / 12)$ & Smart balance master & Balance ability \\
\hline Kim and Park ${ }^{71}$ & Spiral and quadriceps taping (elastic) & $42(21 / 21)$ & 10-meter walk test & Walking ability \\
\hline Park and $\mathrm{Cho}^{15}$ & Trunk taping+scapular setting exercise & $20(10 / 10)$ & Manual function test of upper extremity & Upper extremity function \\
\hline
\end{tabular}


근 I자와 Y자 테이핑 방법을 사용하여 경직의 감소에 변화를 보였다. Carda 등 ${ }^{30}$ 은 보툴리눔 독소 타입 A (botulinum toxin type A) 이후 테 이핑을 병행한 집단에서 경직의 감소와 함께 보행능력 및 관절가동 범위 향상을 보였으며, 다른 캐스팅(casting)과 스트레칭 집단보다 오 래 지속되는 결과를 제공하였다. 테이핑의 효과 중 테이프 주름은 표 피를 들어올려 혈액순환을 증진시킬 수 있다. 따라서 경직을 위한 테 이핑은 경직이 발생되는 근육의 수축을 보조하여 근육의 힘줄에 위 치한 골지건기관의 자극을 통해 $\alpha$-운동신경원의 흥분성을 감소시켜 경직을 감소시킨 것으로 생각되며, 운동 후 근 수축과 테이핑으로 인 한 혈류량 증가가 영향을 미쳐 나타난 결과라 사료된다(Table 1). ${ }^{29}$

\section{3) 고유수용성감각 증가}

뇌졸중 환자는 일반적으로 $50 \%$ 정도가 고유수용성감각의 소실을 보 였으며, ${ }^{31}$ 뇌졸중 환자는 정상인보다 자세동요가 더 크다는 연구가 보고되었는데, ${ }^{32}$ 이것은 고유수용성감각 정보의 통합이 어렵기 때문 이다.33,34 이러한 고유수용성감각 정보의 통합은 뇌졸중 환자의 신체 활동능력을 개선시킬 수 있는 효과적인 방법이 될 수 있다. ${ }^{35}$ 또한, 뇌 졸중 이후 근 마비와 통증 등으로 움직임이 감소되면 손상측의 고유 수용성감각에 부정적인 영향을 미친다. ${ }^{36}$ 이러한 고유수용성감각은 근육이 지속적으로 자극될 때 향상되기 때문에, ${ }^{37}$ 테이핑은 근육에 부착되어 지속적으로 근 활성을 촉진할 수 있으며, 고유수용성감각 의 손상에 대한 기본적인 중재방법으로 고려된다. ${ }^{38,39}$ 하지만 Lee와 $\mathrm{Lim}^{40}$ 은 뇌졸중 환자에게 어깨관절 어깨뼈 테이핑을 적용하였지만 고유수용성감각에 유의한 차이를 얻지 못했지만, Choi 등는 신경계 손상에 따른 환자의 재활 치료 전에 테이핑의 적용이 고유수용성감 각 향상에 긍정적 영향을 미친다고 보고하였다. 따라서 테이핑과 함 께 보조적인 운동을 적용한다면 고유수용성감각의 변화가 유의한 향상을 얻을 수 있으며, 선행연구에서처럼 운동을 통한 근육의 활동 이 동반된다면 고유수용성감각 향상에 더욱 긍정적인 영향을 미칠 것으로 사료된다(Table 1).

\section{4) 통증 감소}

뇌졸중으로 인한 편마비 환자들은 불능하게 된 손상측 팔과 다리를 무시하고, 비손상측만을 사용하게 됨으로 손상측의 근육위축을 초 래하게 된다. 이로 인해 어깨관절은 가동범위가 감소될 뿐만 아니라, 손상측의 이완성 마비로 인해 중력에 대한 저항이 감소되면서 어깨 관절의 아탈구와 근력약화, 경직 등이 초래되어 심한 어깨관절 통증 을 호소하게 된다. ${ }^{42}$

편마비 환자의 어깨관절 아탈구로 인한 통증 감소와 예방을 위한 중재방법으로는 슬링(sing)이 사용되고 있으나 그 효과에 대한 의견 이 다양하다.43,44 그러나 어깨관절 테이핑방법은 아탈구된 편마비 환
자의 어깨관절을 지지해 줌으로써 어깨관절 아탈구를 보호하고 예 방하며 어깨관절의 통증을 감소시키는 중재방법 중의 하나로 사용 되어지고 있다. 45,46 편마비 환자의 테이핑 중재가 어깨관절 아탈구와 통증 감소에 효과적이고, 다른 중재방법과 병행하여 테이핑 적용이 필요하다고 하였으며, ${ }^{47-49} \mathrm{Lee}$ 등 ${ }^{48}$ 은 어깨통증이 있는 뇌졸중 환자에 게 테이핑 중재는 어깨 통증과 장애 지수 및 관절가동범위가 개선되 었으며, 테이핑 중재는 편마비 환자의 어깨 통증을 감소시키는 대체 치료법이라고 하였다. Kang과 $\mathrm{Kim}^{14}$ 은 테이핑 중재가 안정 시와 동작 시 통증 정도가 유의하게 감소되어 테이핑 중재가 통증을 감소시키 는 데 효과가 있음을 확인할 수 있었다고 보고하였다. 이러한 테이핑 적용에 따른 통증감소는 $\mathrm{Aeo}^{50}$ 는 통증이 있을 때 근육방향에 따른 피부표면에 테이프를 부착하면 지속적으로 피부를 자극하여 C섬유 에서 유래되는 통증의 전달을 방해하여 척수반사를 차단함으로써 통증이 감소된다고 하였고, 또한, Lee ${ }^{51}$ 도 피부표면이 신장된 상태에 서 테이프를 부착한 후 피부를 이완하면 테이프에 의해 주름이 생기 게 되고, 이로 인해 피부와 근막 사이의 공간이 확보되어 손상부위나 통증 부위 근육에 혈액공급이 원활해짐으로 통증이 완화될 수 있다 고 하여 선행연구들의 결과를 뒷받침한다(Table 1).

\section{5) 관절가동범위 증가}

뇌졸중 환자의 대부분이 경험하고 있는 편마비는 감각마비, 실행증, 반맹증, 실어증, 실인증을 동반할 뿐만 아니라, 몸의 한쪽을 사용하지 못하므로 강직성 마비와 관절가동범위의 감소를 초래하여 일상생활 수행을 독립적으로 하지 못하고 의존상태로 지내게 된다. 또한 운동 장애로 인한 수의근 조절이 상실된 경우 굽힘근과 폄근의 불균형을 초래하여 심각한 장애를 초래하게 된다.52 또한, 뇌졸중 환자의 어깨 의 경우 근육마비로 팔의 무게를 지탱할 수 없어 관절가동범위가 제 한될 뿐만 아니라, 어깨관절의 아탈구와 경축이 초래되어 심한 어깨 관절 통증을 나타낸다. 따라서 관절가동범위에 대한 적극적인 중재 가 요구된다. ${ }^{33}$ 관절가동범위 향상을 의한 중재방법으로 테이핑 방법 이 보고되고 있으며, ${ }^{44,55}$ 뇌졸중 환자를 대상으로 한 선행연구들을 살펴보면, Lee와 $\mathrm{Lim}^{22}$ 은 어깨관절을 올림하는 동안 아급성 편마비 환자들에게 적용한 어깨빼 테이핑은 어깨뼈 앞쪽 올림의 근 활성도 와 관절가동범위를 증가시키는 데 부가적인 중재 방법으로 활용될 수 있으며, 관절가동범위 증가는 테이핑 적용 후 어깨뼈 앞쪽 올림의 근 활성도 증가와 통증감소로 인하여 증가된 것으로 보고하였다. Kang과 $\mathrm{Kim}^{14}$ 은 어깨관절 가동범위는 테이핑 중재를 받은 실험군이 대조군에 비해 어깨관절 굽힘과 벌림 정도가 유의하게 증가되었다고 보고하였으며, 테이핑이 어깨의 관절가동범위 제한이 있는 편마비 환자에 효과가 있음을 확인할 수 있었다. $\mathrm{AeO}^{50}$ 의 휴지모터반사이론 에 근거하여, 관절가동범위가 제한된 근육 부위에 테이프를 부착하 
면 미세한 수축을 일으켜 근육의 균형상태를 조화롭게 해주는 원리 로서, 이는 관절주변의 긴장된 근육을 이완시키고 관절에 가해지는 압박력을 조절하여 통증이 감소되고 관절가동범위를 증가시키는 효 과 때문인 것으로 사료된다(Table 1).

\section{3. 탄성 테이핑과 신체활동의 효과}

\section{1) 자세안정성과 균형능력 향상}

뇌졸중으로 인한 신경학적 손상으로 대부분의 환자들은 균형유지 에 장애를 갖는다. ${ }^{56}$ 뇌졸중으로 인한 편마비는 신체 좌우 비대칭으 로 서 있는 동안 전체 체중의 $30-40 \%$ 정도를 손상측 다리로 지지하게 되므로 불안정한 선 자세는 물론 균형능력의 질적 저하 등 다양한 문 제를 발생하게 된다.5758 이러한 비대칭적인 체중 지지로 인해 이마면 에서 자세 동요가 증가되고, ${ }^{59}$ 몸의 동요가 클수록 움직임의 정확도 도 떨어지게 된다.60 뇌졸중 환자의 자세동요에 영향을 미치는 원인으 로는 전정기능과 시각 및 발목과 같은 관절의 고유수용감각 저하에 있다. ${ }^{11}$ 이러한 뇌졸중 환자의 균형을 증진시킬 목적으로 고유수용성 감각 훈련과 함께 다리 근육에 테이핑을 이용한 중재가 이루어지고 있으며, ${ }^{62}$ 선행연구들을 살펴보면 다음과 같다. Ekiz 등른 편마비 환 자의 넙다리네갈래근(quadriceps muscles)에 테이핑과 함께 4 주간 일 반적 재활운동을 병행하여 진행한 결과 균형능력에 유의한 향상을 보였다. Choi 등ㄴㅣㅡㄴ 무릎뼈 아래 미끄러짐 테이핑(patella inferior gliding taping), 무릎뼈 안쪽 미끄러짐 테이핑(patella medial glidingtaping) 및 넙다리네갈래근 테이핑(quadricepsmuscle taping)을 부착하여 4 주 동안 고유수용성신경근촉진법(proprioceptive neuromuscular facilitation) 프로그램을 병행한 결과 균형능력에 유의한 향상을 보였다. 무 릎뼈 테이핑은 넙다리네갈래근의 근력을 보조하여 무릎에 부하를 감소시키므로 무릎관절에 안정성을 증가시켜 ${ }^{63}$ 보행능력에 향상을 보인 것으로 생각된다. $\mathrm{Oh}$ 등 ${ }^{16}$ 은 뇌졸중 환자의 무릎에 나선형 관절 테이핑과 넙다리네갈래근 테이핑을 적용한 결과 두 방법 모두 균형 능력에 증가를 보였다. 이와 같이 선행연구들에서 테이핑을 적용한 후 뇌졸중 환자의 균형능력 개선에 효과를 확인하였으며 테이핑 효 과에 관한 임상적 의의가 있다(Table 1).

\section{2) 보행능력 향상}

뇌졸중 환자는 섬세한 운동조절능력의 소실로 인하여 느린 움직임 과 이에 대한 손상측의 보상 작용, 고유수용감각 손상, 경직 등은 발 목관절의 발등굽힘을 어렵게 하여 발목처짐(foot drop)을 유발하며, ${ }^{64}$ 무릎 폄근과 굽힘근의 경직과 약화로 인해 한 다리 지지기 시 젖힌 무 릎(genu recurvatum)이 나타나고, ${ }^{65}$ 이에 대한 비정상적 협응은 굽힘 근 공동운동(mass flexor pattern) 또는 폄근 공동운동(mass extensor pattern)을 유발하며 편마비 보행이라는 특징적인 보행형태를 보이게
된다. ${ }^{66}$ 따라서 느린 보행주기(gait cycle)와 보행속도, 보폭(stride length)의 감소, 손상측과 비손상측 간 보폭 차이, 손상측의 상대적으 로 짧은 디딤기(stance phase)와 긴 흔듦기(swing phase) 등의 보행특성 을 나타낸다.67 이처럼 뇌졸중 환자는 손상측과 비손상측 무릎 굽힘 및 폄근 근력약화가 정상인에 비해 저하를 보이고 ${ }^{68}$ 무릎 주변 근력 증진이 보행능력의 예측변수인 것으로 볼 때, ${ }^{69}$ 정상적인 보행패턴을 달성하기 위해서는 무릎 주변 근력을 개선시켜야 한다. 또한, 뇌졸중 환자는 정상인과 노인에 비해 평상시, 근 피로 시 무릎의 고유수용감 각 저하가 나타나므로 무릎 근 피로를 제한하고, ${ }^{70}$ 보행능력을 향상시 키는 방법이 필요하다

Ekiz 등12은 편마비 환자의 넙다리네갈래근(quadriceps muscles)에 테이핑과 함께 4 주간 일반적 재활운동을 병행하여 진행한 결과 보행 능력에 유의한 향상을 보였다. Kim과 Park ${ }^{71}$ 은 뇌졸중 환자를 대상으 로 나선형(spiral) 테이핑과 넙다리네갈래근 테이핑을 적용한 결과 10 $\mathrm{m}$ 보행(10 meter walk), 동적 보행 지수(dynamic gait index), 보행률 및 보행 속도에 유의한 향상을 보였다. 나선형 테이핑 방법이 넙다리와 아래다리 사이 한쪽방향으로 돌아가는 전단력을 조절하여르 뇌졸중 환자의 보행능력을 향상시킨 것으로 생각되며, 테이핑은 보조기에 비 해 비용이 적게 발생하고 다양한 대상자의 신체크기에 누구나 손쉽 게 적용이 가능하다. ${ }^{71}$ Choi 등 41 은 무릎뼈 미끄러짐 테이핑(patellagliding taping)과 넙다리네갈래근 테이핑(quadricepsmuscle taping)을 부착한 후 4 주간 고유수용성신경근촉진법(proprioceptive neuromuscular facilitation) 운동을 실시한 결과 보행능력에 유의한 향상을 보였 다. 이와 같이 테이핑은 보조기와는 다르게 많은 비용과 신체둘레의 변화에 따라 새롭게 제작해야 하는 번거로움이 없이 저비용으로 누 구나 손쉽게 적용하여 보행능력의 향상을 위한 중재방법으로 이용 될 수 있다(Table 1).

\section{3) 팔 기능 향상}

뇌졸중 환자는 $80 \%$ 이상에서 편마비를 경험하고 다리보다 팔에서 더 많은 약화를 보이며 약 $88 \%$ 가 팔의 기능적 장애를 경험하고 있 다. ${ }^{2.73}$ 일반적으로 어깨관절에서 정상적인 움직임을 위해서는 오목위 팔관절(glenohumeral joint), 봉우리빗장관절(acromioclavicular joint), 복장빗장관절(sternoclavicular joint), 그리고 어깨가슴관절(scapulothoracicjoint)의 세밀한 조화 및 조절된 움직임을 필요로 하며, ${ }^{74}$ 특히 팔을 앞쪽올림 하는 데 있어 어깨뼈 위쪽돌림은 필수적인 구성 요소 이다. ${ }^{75}$ 어깨뼈 위쪽돌림이 완전하게 일어나기 위해서는 위등세모근, 아래등세모근, 앞톱니근이 전체 관절가동범위 동안 협력해야 한다. ${ }^{76}$ 그러나 팔을 앞쪽으로 움직임에 있어 주요한 근육인 앞톱니근은 몸 통과 어깨를 연결시켜 주는 근육으로 뇌졸중 환자의 경우 이 근육에 약화가 두드러지게 나타나고, ${ }^{3}$ 근 수축 패턴이 바뀌게 되어 어깨뼈의 
운동학적 변화를 보인다. ${ }^{4}$ 이와 같은 문제점을 개선하여 팔 기능의 향 상을 위한 방법으로 테이핑은 근육과 관절을 원하는 방향으로 정렬 시켜 관절의 정상적인 움직임과 근육의 기능을 향상시킨다. ${ }^{77}$ 테이핑 이 팔의 기능증진에 미치는 영향에 대한 선행연구를 살펴보면, Park 과 $\mathrm{Cho}^{15}$ 는 비 손상측 척추세움근에 몸통 교정 테이핑과 어깨뼈 설정 운동을 실시한 결과 몸통근육의 활성과 몸통손상척도의 개선으로 팔 기능의 향상을 보였다. 앞톱니근의 약화를 보이는 ${ }^{3}$ 뇌졸중 환자를 대상으로 Lee와 $\mathrm{Lim}^{22}$ 은 손상측어깨에 비탄력테이핑을 적용하여 앞 톱니근의 활성을 증가시켜 팔 기능에 도움이 되는 테이핑 방법을 소 개하였다. $\mathrm{Go}^{78}$ 에 의하면, 테이핑 이론으로 골지건과 근방추반사설이 있으며 골지건은 근육과 건의 지나친 수축을 막아주고, 근방추반사 는 근육이 지나치게 늘어나는 것을 방지하여 근육의 긴장성조절, 자 세조절, 신체의 평형조절에 중요한 역할을 하게 되며, 선행연구들에 서도 골지건과 근방추반사설에 의해 긴장된 근육과 약화된 근육 간 에 평형을 이뤄 팔의 기능 향상에 영향을 미친 것으로 사료되며, 앞으 로 뒷받침한 연구들이 필요하다(Table 1).

\section{결 론}

본 연구는 선행연구들을 바탕으로 뇌졸중 환자에 대한 테이핑의 신 체적 기능과 활동에 대한 효과를 분석하였다. 뇌졸중 환자는 일반적 으로 팔의 경우 폄근의 약화가 크게 나타나 상대적으로 굽힘근의 긴 장이 크고, 다리의 경우 굽힘근의 약화로 폄근의 긴장이 큰 것이 일반 적이다. 뇌졸중 환자에게 탄성 테이프를 적용하여 팔에서는 굽힘근 과 같은 강한 근육은 이완을 목적으로 적용하였으며, 폄근과 같은 약 한 근육은 근력의 증가를 목적으로 적용되었으며, 다리에서도 팔과 같이 유사하게 적용되었다. 이와 같은 적용방법에 따른 뇌졸중 환자 의 탄성 테이핑의 신체 기능적 효과에서는 근력 증가, 경직 감소, 고유 수용감각 증가, 통증 감소 및 관절가동범위 증가를 보였다. 또한, 탄성 테이핑에 의한 신체 기능의 향상에 의한 신체 활동적 효과에서는 환 자 치료의 목표가 되는 균형과 보행능력 및 팔 기능의 향상을 보였다. 신체 기능과 활동을 향상시킬 수 있었던 배경은 첫째는 테이프가 가 지고 있는 탄성에 의해 피부와 근육이 자극을 받음으로써 긴장되어 있던 근육이 원래의 상태로 되돌아가기 때문에 근육의 기능이 정상 화된 것으로 보이고, 근육이 긴장되어 관절이 어긋나는 경우가 있는 데, 테이프를 붙임으로써 근육의 긴장이 정상상태로 되돌아오므로 관절이 어긋나는 것을 예방된 것으로 보인다. 둘째는 테이프가 피부 를 들어 올려 주름을 형성하여 국소에 고여 있던 조직액 등이 빨리 배출되고 혈액이나 림프액의 흐름이 원활하게 되어 각종 문제점에 개 선을 보인 것으로 보이며, 셋째는 통증이 있는 부위에 테이프를 붙임 으로써 신경학적으로 통증을 없애는 효과가 있다는 것으로 보인다.
따라서 뇌졸중 환자의 재활과정에서 탄성 테이핑을 활용한다면 더 효과적인 중재방법으로 발전될 수 있으며 다양한 테이핑 방법 개발 이요구된다.

\section{참고문헌}

1. Roh SG, Kim JH. Acute cerebrovascular accident in Korea. J Korea Conv Soc. 2012;3(4):23-8.

2. Rathore SS, Hinn AR, Cooper LS et al. Characterization of incident stroke signs and symptoms: Findings from the atherosclerosis risk in communities study. Stroke. 2002;33(11):2718-21.

3. Jeong JR, Lee WH. The study of asymmetrical of the serratus anterior and lower trapezius muscles in chronic stroke patients. J Korean Soc Phys Med. 2015;10(4):81-90.

4. De Baets L, Van Deun S, Monari D et al. Three-dimensional kinematics of the scapula and trunk, and associated scapular muscle timing in individuals with stroke. Hum Mov Sci. 2016;48:82-90.

5. Dickstein R, Shefi S, Marcovitz E et al. Anticipatory postural adjustment in selected trunk muscles in poststroke hemiparetic patients. Arch Phys Med Rehabil. 2004;85(2):261-7.

6. Dickstein R, Shefi S, Marcovitz E et al. Electromyographic activity of voluntarily activated trunk flexor and extensor muscles in post-stroke hemiparetic subjects. Clin Neurophysiol. 2004;115(4):790-6.

7. Kim SM. The effects of taping on musculoskeletal system pain and dysfunction. Int J Coach Sci. 2007;9(3):81-93.

8. Jaraczewska E, Long C. Kinesio ${ }^{\circledR}$ taping in stroke: Improving functional use of the upper extremity in hemiplegia. Top Stroke Rehabil. 2006; 13(3):31-42.

9. Yoshida A, Kahanov L. The effect of Kinesio taping on lower trunk range of motions. Res Sports Med. 2007;15(2):103-12.

10. Kim S, Kim H. The effects of a Kinesio taping on muscle activity and muscle fatigue in quadriceps femoris. J Sport Leis Stud. 2016;63:663-71.

11. Kim WI, Choi YK, Lee JH et al. The effect of muscle facilitation using Kinesio taping on walking and balance of stroke patients. J Phys Ther Sci. 2014;26(11):1831-4.

12. Ekiz T, Aslan MD, Özgirgin N. Effects of Kinesio tape application to quadriceps muscles on isokinetic muscle strength, gait, and functional parameters in patients with stroke. J Rehabil Res Dev. 2015;52(3):32331.

13. Kim MK, Ji SK, Jun HJ et al. The effect of modified CIMT combined with Kinesio-taping on upper limb function in hemiplegic patients. J Korean Soc Phys Med. 2009;4(3):183-92.

14. Kang SI, Kim IS. Effects of a taping therapy on shoulder range of motion and pain, physical function and depression of stroke patients with hemiplegia. Korean J Adult Nurs. 2012;24(3):294-304.

15. Park SJ, Cho KH. The effects trunk correction taping on trunk muscle activity and stability, upper extremity function in stroke patients. J Digital Convergence. 2017;15(2):411-9.

16. Oh KA, Jeon DJ, Lee BH et al. The effect on improving static balance ability according to elastic taping methods in stroke patients with hemiplegia. J Exerc Rehabil. 2011;7(3):81-8.

17. Lundy-Ekman, L. Neuroscience-E-Book: Fundamentals for rehabilita- 
tion. Amsterdam, Elsevier Health Sciences, 2013.

18. Shumway-Cook A, Woollacott MH. Motor control: Translating research into clinical practice. Philadelphia, Lippincott Williams and Wilkins, 2007.

19. Runge C, Shupert C, Horak F et al. Ankle and hip postural strategies defined by joint torques. Gait Posture. 1999;10(2):161-70.

20. Chen B, Bates BT. Comparison of F-Scan in-sole and AMTI forceplate system in measuring vertical ground reaction force during gait. Physiother Theory Pract. 2000;16(1):43-53.

21. Vithoulka I, Beneka A, Malliou P et al. The effects of Kinesio-taping ${ }^{\circledR}$ on quadriceps strength during isokinetic exercise in healthy non athlete women. Isokinet Exerc Sci. 2010;18(1):1-6.

22. Lee JN, Lim CG. Effects of scapular taping on muscle activity, pain, range of motion and proprioception in subacute stroke patients. J Korea Acad coop Soc. 2013;14(11):5689-97.

23. Kim Y. Physical therapy diagnostics: Musculoskeletal assessment. Seoul, Young Moon, 2001.

24. Vattanasilp W, Ada L, Crosbie J. Contribution of thixotropy, spasticity, and contracture to ankle stiffness after stroke. J Neurol Neurosurg Psychiatry. 2000;69(1):34-9.

25. Jang GU, Kweon MG, Park S et al. A study of structural foot deformity in stroke patients. J Phys Ther Sci. 2015;27(1):191-4.

26. Caillet F, Mertens P, Rabaseda S et al. Three dimensional gait analysis and controlling spastic foot on stroke patients. Ann Readapt Med Phys. 2003;46(3):119-31.

27. Kwon HC. A study of various factors influencing standing balance of independent ambulatory hemiparetic patients. J Kor Phys Ther. 1989; 1(1):15-25.

28. Tamburella F, Scivoletto G, Molinari M. Somatosensory inputs by application of Kinesio taping: effects on spasticity, balance, and gait in chronic spinal cord injury. Front Hum Neurosci. 2014;8:367.

29. Park SJ, Kim TH, Go JH et al. The impact of convergence balance training and taping on spasticity and balance ability in patients with chronic stroke. J Digital Convergence. 2017;15(7):297-306.

30. Carda S, Invernizzi M, Baricich A et al. Casting, taping or stretching after botulinum toxin type A for spastic equinus foot: A single-blind randomized trial on adult stroke patients. Clin Rehabil. 2011;25(12):1119-27.

31. Carey LM, Matyas TA, Oke LE. Sensory loss in stroke patients: Effective training of tactile and proprioceptive discrimination. Arch Phys Med Rehabil. 1993;74(6):602-11.

32. Rode G, Tiliket C, Boisson D. Predominance of postural imbalance in left hemiparetic patients. Scand J Rehabil Med. 1997;29(1):11-6.

33. Di Fabio RP, Badke MB. Stance duration under sensory conflict conditions in patients with hemiplegia. Arch Phys Med Rehabil. 1991; 72(5):292-5.

34. Pérennou DA, Leblond C, Amblard B et al. The polymodal sensory cortex is crucial for controlling lateral postural stability: Evidence from stroke patients. Brain Res Bull. 2000;53(3):359-65.

35. Priplata AA, Patritti BL, Niemi JB et al. Noise-enhanced balance control in patients with diabetes and patients with stroke. Ann Neurol. 2006; 59(1):4-12.

36. Ada L, Ward D, Mackey F et al. Analysis of secondary shoulder dysfunction following stroke. Australian Synapse. 1987:19-21.

37. Swanik KA, Lephart SM, Swanik CB et al. The effects of shoulder plyo- metric training on proprioception and selected muscle performance characteristics. J Shoulder Elbow Surg. 2002;11(6):579-86.

38. Robbins S, Waked E, Rappel R. Ankle taping improves proprioception before and after exercise in young men. Br J Sports Med. 1995;29(4): 242-7.

39. Halseth T, McChesney JW, DeBeliso M et al. The effects of Kinesio ${ }^{\mathrm{TM}}$ taping on proprioception at the ankle. J Sports Sci Med. 2004;3(1):1-7.

40. Lee JN, Lim CG. Effects of scapular taping on muscle activity, pain, range of motion and proprioception in subacute stroke patients. J Korea Acad coop Soc. 2013;14(11):5689-97.

41. Choi YK, Nam CW, Lee JH et al. The effects of taping prior to PNF treatment on lower extremity proprioception of hemiplegic patients. J Phys Ther Sci. 2013;25(9):1119-22.

42. Gracies JM, Marosszeky JE, Renton R et al. Short-term effects of dynamic lycra splints on upper limb in hemiplegic patients. Arch Phys Med Rehabil. 2000;81(12):1547-55.

43. Brooke MM, de Lateur BJ, Diana-Rigby GC et al. Shoulder subluxation in hemiplegia: Effects of three different supports. Arch Phys Med Rehabil. 1991;72(8):582-6.

44. Williams R, Taffs L, Minuk T. Evaluation of two support methods for the subluxated shoulder of hemiplegic patients. Phys Ther. 1988;68(8):120914.

45. Peterson C. The use of electrical stimulation and taping to address shoulder subluxation for a patient with central cord syndrome. Phys Ther. 2004;84(7):634-43.

46. Walsh K. Management of shoulder pain in patients with stroke. Postgrad Med J. 2001;77(912):645-9.

47. Lee JH, Lee GC, Kim YK. The effect of taping therapy on shoulder in hemiplegic patients. J Korean Acad Phys Ther Sci. 2002;9(3):89-96.

48. Lee SH, Lee JS, Kim SS et al. The effect of scapular girdle taping on hemiplegic shoulder pain: a clinical study. J Korean Med. 2000;39(3):115-26.

49. Huang YC, Chang KH, Liou TH et al. Effects of Kinesio taping for stroke patients with hemiplegic shoulder pain: A double-blind, randomized, placebo-controlled study. J Rehabil Med. 2017;49(3):208-15.

50. Aeo G. Balance taping therapy of Aeo Gang. Seoul, Green care, 2001.

51. Lee G. Clinical integration based on the symposium (pain): Taping therapy. Korean Neurological Association 30th General Congress of Neurology, 2002.

52. Pang MY, Eng JJ, Miller WC. Determinants of satisfaction with community reintegration in older adults with chronic stroke: Role of balance self-efficacy. Phys Ther. 2007;87(3):282-91.

53. Lindgren I, Jönsson AC, Norrving B et al. Shoulder pain after stroke: A prospective population-based study. Stroke. 2007;38(2):343-8.

54. Host HH. Scapular taping in the treatment of anterior shoulder impingement. Phys Ther. 1995;75(9):803-12.

55. Shamus JL, Shamus EC. A taping technique for the treatment of acromioclavicular joint sprains: A case study. J Orthop Sports Phys Ther. 1997;25(6):390-4.

56. Tyson SF, Hanley M, Chillala J et al. Balance disability after stroke. Phys Ther. 2006;86(1):30-8.

57. Bohannon RW, Larkin PA. Lower extremity weight bearing under various standing conditions in independently ambulatory patients with hemiparesis. Phys Ther. 1985;65(9):1323-5.

58. Sharp SA, Brouwer BJ. Isokinetic strength training of the hemiparetic 
knee: Effects on function and spasticity. Arch Phys Med Rehabil. 1997; 78(11):1231-6.

59. Geurts AC, de Haart M, van Nes IJ et al. A review of standing balance recovery from stroke. Gait Posture. 2005;22(3):267-81.

60 . Nichols DS. Balance retraining after stroke using force platform biofeedback. Phys Ther. 1997;77(5):553-8.

61. Niam S, Cheung W, Sullivan PE et al. Balance and physical impairments after stroke. Arch Phys Med Rehabil. 1999;80(10):1227-33.

62. Kim YR. Effect of lower leg taping on balance and gait ability in stroke patients. Hallym University. Dissertation of Master's Degree. 2012.

63. Lee YS, Kwak CS, Lee CI et al. Effects of lower extremity stability by Kinesio taping method in elite speed skating athletesone-leg jumping. J Digital Convergence. 2015;13(8):495-502.

64. Lehmann JF, Condon SM, Price R. Gait abnormalities in hemiplegia: Their correction by ankle-foot orthoses. Arch Phys Med Rehabil. 1987; 68(11):763-71.

65. Bleyenheuft C, Bleyenheuft Y, Hanson P et al. Treatment of genu recurvatum in hemiparetic adult patients: A systematic literature review. Ann Phys Rehabil Med. 2010;53(3):189-99.

66. Norkin C, Levangie P. Gait analysis. In: O’Sullivan SB, Schmitz TJ. Physical rehabilitation: assessment and treatment. 3rd ed. Philadelphia, FA Davis, 1994

67. Ryerson S, Levit K. Functional movement reeducation: a contemporary model for stroke rehabilitation. London, Churchill Livingstone, 1997.

68. Choi HH. Functional isokinetic strength ratios of the quadriceps and hamstrings in individuals with chronic poststroke hemiparesis. J Adapt Phys Activ Exerc. 2005;13(4):135-47.
69. Flansbjer UB, Downham D, Lexell J. Knee muscle strength, gait performance, and perceived participation after stroke. Arch Phys Med Rehabil. 2006;87(7):974-80.

70. Kwon OS, Lee SW, Seo DK et al. The effects of exercise-induced fatigue on knee joint position sense in the young, elderly adults and stroke patients. J Korean Soc Phys Med. 2013;8(4):619-25.

71. Kim DD, Park SJ. The immediate effects of spiral taping on improvement of gait ability in patients with chronic stroke. J Digital Convergence. 2017;15(4):529-36.

72. Langendoen J, Fleish-man C, Kim SH et al. Rationales and evidence of elastic taping: A clinician's per-spective. J Int Acad of Phys Ther Res. 2016;7(1):979-88.

73. Pedretti LW, Early MB. Occupational therapy: Practice skills for physical dysfunction. London, Mosby, 2001.

74. Paine RM, Voight M. The role of the scapula. J Orthop Sports Phys Ther. 1993;18(1):386-91.

75. Neumann DA. Kinesiology of the musculoskeletal system-e-book: Foundations for rehabilitation. Amsterdam, Elsevier Health Sciences, 2013.

76. Ebaugh DD, McClure PW, Karduna AR. Three-dimensional scapulothoracic motion during active and passive arm elevation. Clin Biomech. 2005;20(7):700-9.

77. Campolo M, Babu J, Dmochowska K et al. A comparison of two taping techniques (Kinesio and Mcconnell) and their effect on anterior knee pain during functional activities. Int J Sports Phys Ther. 2013;8(2):10510.

78. Go D. Backyard Kinesio taping therapy. Seoul, Pureunsol, 2011. 